\title{
Dynamic Deformation Properties of Geotextile-Reinforced Sands
}

\author{
Ali Shafiee ${ }^{1}$, Javad Jalili ${ }^{2}$ \\ ${ }^{1}$ California State Polytechnique University, Pomona \\ $3801 \mathrm{~W}$ Temple Ave, Pomona, CA, USA \\ ashafiee@cpp.edu \\ ${ }^{2}$ International Institute of Earthquake Engineering and Seismology \\ No.21 Arghavan, North Dibaji, Tehran, Iran \\ jalili@iiees.ac.ir
}

\begin{abstract}
Resonant column and hollow cylinder torsional shear tests were carried out on geotextile-reinforced sand to investigate shear modulus and damping characteristics of the reinforced sands. The tests were carried out on unreinforced and reinforced specimens with 2, 3 and 4 geotextile sheets under various confining pressures. Test results show that geotextile makes sand stiffer, in such a manner that shear modulus increases with number of geotextile sheets. A power function can describe increase of maximum shear modulus with confining pressure and number of geotextile sheets. On the other hand, damping ratio increases with number of geotextile sheets, and decreases with confining pressure. In addition, scale effect is investigated by extrapolating the lab results to in-situ conditions.
\end{abstract}

Keywords: Geotextile, Sand, Shear Modulus, Damping Ratio, Scale Effect.

\section{Introduction}

Reinforcement with geosynthetics has gained in popularity due to its versatile applications in various problems such as retaining walls, pavements, foundations, and embankments [1]. Geotextiles improve mechanical properties of the soils through friction with the soil, contributing to the shear resistance depending on the direction of the failure plane with respect to the reinforcements, and providing confining pressure through limiting lateral deformations [2]. With regard to the cost of the in situ tests on geosynthetic-reinforced soils, there is more tendency to use physical modelling in different scales, however, in some cases, element testing have been carried out to qualitatively evaluate mechanical behaviour of geosynthetic-reinforced soils $[3,4,5]$.

Although there are a few cases reporting mechanically stabilized earth (MSE) failure [6], MSE retaining walls and slope structures are generally assumed resistant to earthquakes due to their flexibility [7]. However, there is a need to evaluate shear modulus reduction and damping properties of reinforced soils to estimate retaining wall seismic acceleration considering wave scattering, and wall displacement [8,9]. In addition, pseudo-static external stability of MSE walls depends on the seismic coefficient $(\mathrm{k})$, which is a parameter highly dependent on the stiffness degradation and damping properties of the reinforced soil [7].

Although there are some studies on the liquefaction potential of geotextile-reinforced sands [10,11], there are a few studies addressing dynamic deformation properties (i.e., shear modulus and damping ratio) of geotextile-reinforced soils. For example, Akbulut and Pamakcu [12] used resonant column tests to show that maximum shear modulus and damping ratio increases with number of geotextile sheets in clays.

This paper aims to study stiffness degradation and damping properties of geotextile-reinforced sands. Clean sand is reinforced with two, three, and four sheets of geotextiles, and then tested in resonant column and cyclic hollow cylinder torsional shear device to evaluate shear modulus and damping ratio of the reinforced sand from very low to high shear strains. The scale effect is also evaluated to show how the results of this study can be extrapolated to in-situ conditions.

\section{Tested Materials and Procedures}

A silica sand was selected to be reinforced with geotextile sheets to investigate shear modulus and damping properties of geotextile-reinforced granular soils. The sand was uniformly graded with a mean grain size, $D_{50}$ of 0.25 $\mathrm{mm}$, coefficient of uniformity, $C_{u}$ of 1.75 and a specific gravity of 2.67. Its grains were sub-angular to sub-rounded in shape. It had a maximum and minimum void ratio of 0.82 , and 0.43 respectively. Two, three or four sheets of a woven 
geotextile (weight per unit area $=200 \mathrm{gr} / \mathrm{m}^{2}$, and thickness $=1.2 \mathrm{~mm}$ ) produced from polypropylene were inserted between the soil layers. Each geotextile sheet had a longitudinal/transverse strength of $12 \mathrm{kN} / \mathrm{m}$ when elongation reaches as high as $50 \%$ or more.

Resonant Column and hollow cylinder torsional shear tests were performed to investigate dynamic deformation properties of geotextile-reinforced sands at low and large shear strains respectively. All the tests were carried out under unconsolidated undrained conditions at various confining pressures of 100,300 , and $500 \mathrm{kPa}$. The sand was reinforced with either 2, 3, or 4 sheets of geotextile (Fig 1). Clean sand specimens were also tested to provide a basis for the comparison of the test results. A total of 24 resonant column, and hollow cylinder torsional shear tests were carried out.

The specimens were compacted in several layers until achieving a relative density of $70 \%$ and a water content of 3\%. After compacting and leveling each layer of soil, the reinforcement was placed horizontally. Diameter of the reinforcement was slightly less than that of the specimen. The resonant column specimens had an identical diameter, and height of $10 \mathrm{~cm}$. The specimens tested in the hollow torsional device had an outside diameter of $10 \mathrm{~cm}$, inside diameter of $5 \mathrm{~cm}$, and a height of $10 \mathrm{~cm}$. All the torsional shear tests were conducted under strain-controlled conditions with a frequency of $0.1 \mathrm{~Hz}$, and continued up to 40 cycles of loading. Shear modulus and damping ratio were calculated at the cycle 10 of loading. The hysteretic loop shown in Fig. 2 corresponds to a single amplitude shear strain of $0.2 \%$, and indicates the equivalent shear modulus and damping ratio during the tenth cycle of loading.
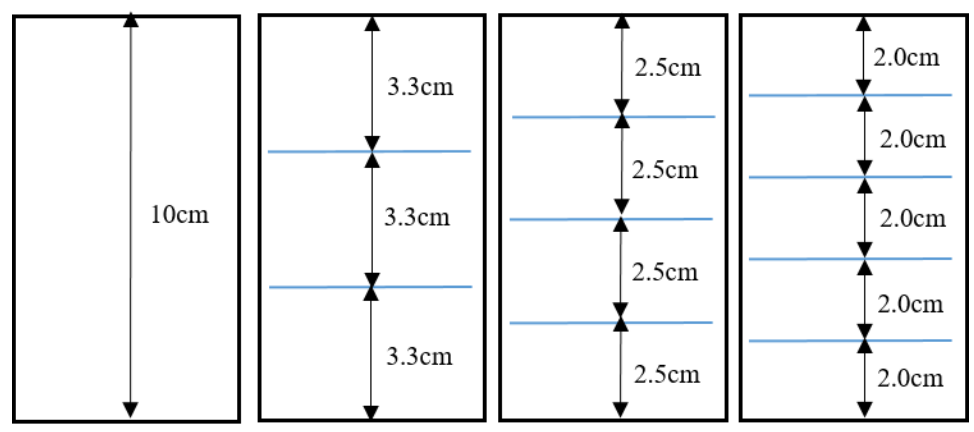

Fig. 1: Geotextile arrangements used in this study.

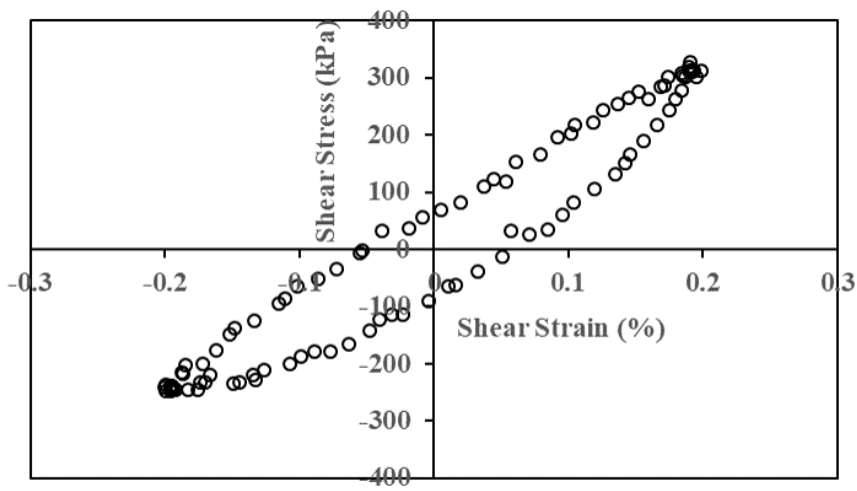

Fig. 2: Cycle 10 of loading on reinforced sand with three sheets of geotextiles, under a confining pressure of $500 \mathrm{kPa}$.

\section{Test Results and Discussion}

Monotonic behaviour of the geotextile-reinforced sand tested in this study has already been investigated through monotonic triaxial compression, triaxial extension, and torsional shear tests [13]. Test results revealed that geotextiles 
improve mechanical properties of the sand, since both strain at failure and undrained shear strength increased with the number of geotextile sheets in sand.

\section{1. Maximum Shear Modulus}

At very low shear strain levels (less than $10^{-3} \%$ ), shear modulus $(G)$, and damping ratio $(D)$ remain essentially constant; shear modulus is at its maximum value $\left(G_{\max }\right)$, and damping ratio at its minimum value $\left(D_{\min }\right)$. On the other hand, many experimental investigations carried out on sandy and normally consolidated clayey soils in early studies [14] showed $G_{\max }$ was basically related to the mean effective principal stress, $p$ and void ratio, $e$ expressed by the well known equation:

$$
\left(\frac{G_{\max }}{P_{a}}\right)=A F(e)\left(\frac{p}{P_{a}}\right)^{\mathrm{n}}
$$

in which $P_{a}$ is atmospheric pressure, $A$ is an empirical constant reflecting soil fabric formed through various stress and strain histories, $n$ is empirically determined exponent, approximately equal to 0.5 , and $F(e)$ is a void ratio function $[14,15]$.

Figure 3 shows variation of $G_{\max }$ in terms of confining pressure in geotextile-reinforced sands. Values of $G_{\max }$ were obtained from resonant column tests at very low shear strains of about $5 \times 10^{-3} \%$. As observed, $G_{\max }$ increases with number of geotextile sheets, and confining pressure. Table 1 presents values of $A F(e)$, and exponent $n$ in Eq. (1) for the tested materials using the least square method. As seen, values of $n$ are very close to 0.5 irrespective of number of geotextile sheets used.

Figure 3 also presents the variation of minimum damping ratio in terms of confining pressure for geotextile-reinforced sands. As may be seen, regardless of the confining pressure minimum damping ratio generally increases with number of geotextile sheets. In addition, $D_{\min }$ decreases with confining stress, which is in accordance with Zhang et al. [16] investigations on the effect of confining pressure on the minimum damping ratio.
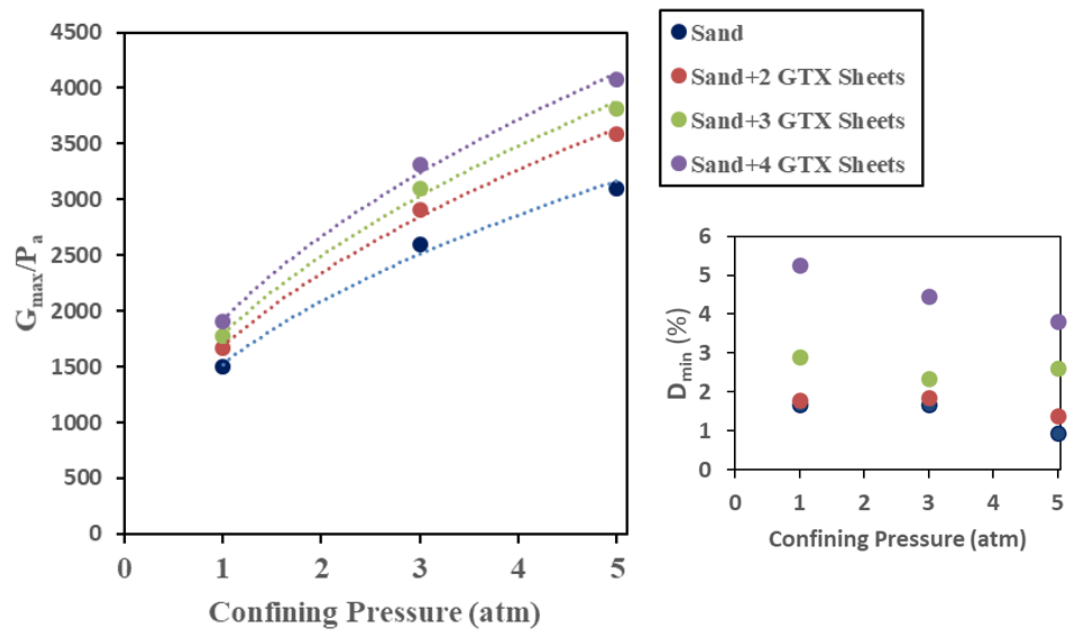

Fig. 3: Maximum shear modulus in geotextile-reinforced sands.

Table 1: Parameters of Eq. (1) for tested materials.

\begin{tabular}{|l|l|l|c|}
\hline Material & $\mathrm{AF}(\mathrm{e})$ & $\mathrm{n}$ & Coefficient of Determination $\left(\mathrm{R}^{2}\right)$ \\
\hline Sand & 1520.4 & 0.457 & 0.99 \\
\hline Sand+2 Geotextile Sheets & 1677.9 & 0.481 & 0.99 \\
\hline Sand+3 Geotextile Sheets & 1787.7 & 0.481 & 0.99 \\
\hline Sand+4 Geotextile Sheets & 1918.4 & 0.477 & 0.99 \\
\hline
\end{tabular}




\section{2. Shear Modulus Characteristics}

Figure 4 shows the plot of equivalent shear modulus $(G)$ versus single amplitude shear strain from 0.0001 to $1.0 \%$ for geotextile-reinforced sands under confining pressures of 100 and $500 \mathrm{kPa}$. It is observed that the results are influenced by number of geotextile sheets and confining pressure. For geotextile-reinforced sands shear modulus increases with number of geotextile sheets, and confining pressure. It appears that the effect of 2 and 3 sheets of geotextiles on the shear modulus is negligible when shear strain level is greater than $0.01 \%$.
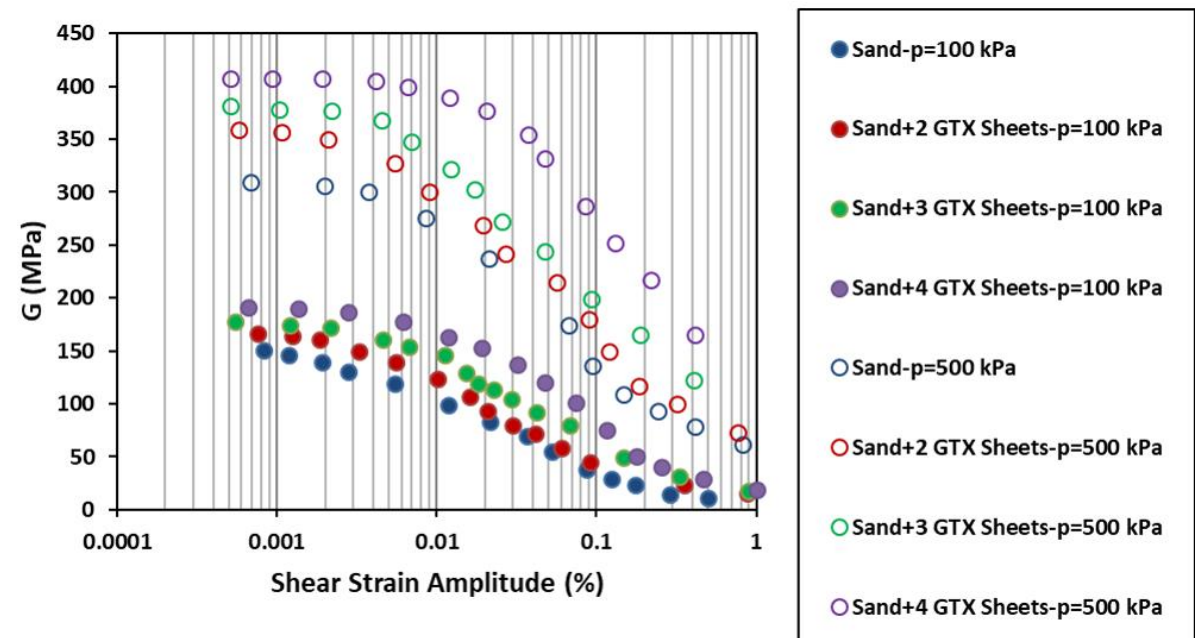

Fig. 4: Shear modulus in geotextile-reinforced sands under confining pressure (p) of 100 and $500 \mathrm{kPa}$.

\section{3. Normalized Shear Modulus and Damping Ratio}

It is customary to represent the variation in shear modulus $(G)$ at any shear strain level by normalizing it with the maximum shear modulus $\left(G_{\max }\right)$. This facilitates comparison of the relationship of soils of different types. Figure 5 presents the strain-dependent normalized shear modulus $G / G_{\max }$ and damping ratio $D$ for the clean sand tested in this study along with modulus reduction and damping curves from Darendeli [17]. As observed, normalized shear modulus matches well with the Darendeli's, however, damping ratios are higher than Darendeli's. Fig. 6 shows the modulus reduction and damping ratio curves for geotextile-reinforced sands under low and high confining pressure of 100 and $500 \mathrm{kPa}$ respectively. It is evident that stiffer (elastic) behavior is captured, when number of geotextile sheets increases, and normalized shear modulus increases with the number of geotextile sheets. On the other hand, damping ratio increases with the number of geotextile sheets, but decreases with confining pressure. 


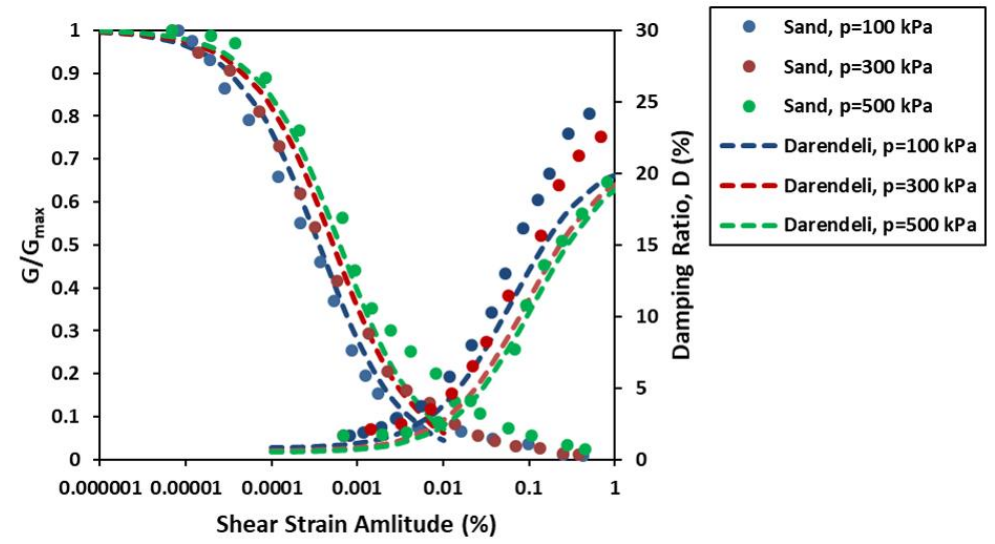

Fig. 5: Modulus reduction and damping curves for the sand tested in this study under various confining stresses (p).
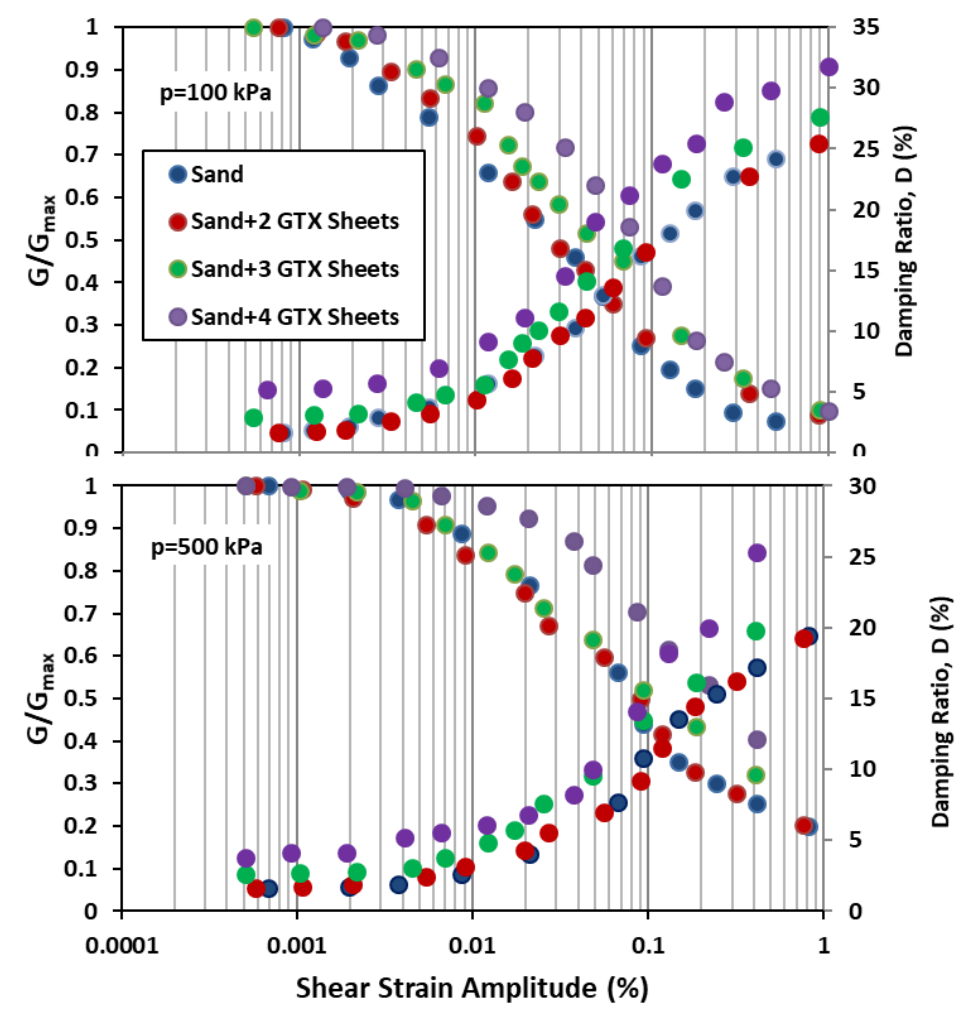

Fig. 6: Modulus reduction and damping curves for geotextile-reinforced sand tested in this study under confining pressures of 100 and $500 \mathrm{kPa}$. 


\section{Scale Effect}

Selection of the appropriate reinforcing material is important in the element testing from scaling point of view. Reducing tensile strength/stiffness of the reinforcing material by a suitable amount helps to represent the in-situ condition accurately. Based on the scale effect rules [18], the relationship between prototype and model reinforcement stiffness can be calculated as follows:

$$
K_{p}=K_{m} \lambda^{2}
$$

where $K_{p}$ and $K_{m}$ are reinforcement stiffness of prototype and model respectively, and $\lambda$ is the scale.

The geotextiles used in this study were not scaled down for element testing, and hence results of this study are subjected to scale effect. However, the results can be extrapolated to account for the scale effect. Table 2 presents the amount of increase in $G_{\max }$ of the parent sand when geotextile sheets are added.

Table 2: Effect of geotextiles on the maximum shear modulus.

\begin{tabular}{|c|c|c|c|c|c|}
\hline Material & $\begin{array}{c}\text { No. of } \\
\text { Geotextile } \\
\text { Sheets per } \\
10 \mathrm{~cm}\end{array}$ & $\begin{array}{c}\text { Confining } \\
\text { Pressure } \\
\text { (atm) }\end{array}$ & $\begin{array}{l}\text { Maximum } \\
\text { Shear Modulus } \\
\text { of Parent Sand } \\
\quad\left(G_{\max } / \mathrm{Pa}\right)\end{array}$ & $\begin{array}{c}\text { Increase in } \\
G_{\max } \text { due to } \\
\text { Geotextile } \\
\text { Reinforcement } \\
(\%) \\
\end{array}$ & $\begin{array}{c}\text { Average } \\
\text { Increase } \\
\text { in } G_{\max } \\
(\%)\end{array}$ \\
\hline Sand & 0 & 1 & 1504 & 0 & \multirow{3}{*}{0} \\
\hline Sand & 0 & 3 & 2601 & 0 & \\
\hline Sand & 0 & 5 & 3095 & 0 & \\
\hline Sand+2GTX Sheets & 2 & 1 & 1668 & 10.9 & \multirow{3}{*}{12.9} \\
\hline Sand+2GTX Sheets & 2 & 3 & 2903 & 11.6 & \\
\hline Sand+2GTX Sheets & 2 & 5 & 3591 & 16.0 & \\
\hline Sand+3GTX Sheets & 3 & 1 & 1775 & 18.0 & \multirow{3}{*}{20.2} \\
\hline Sand+3GTX Sheets & 3 & 3 & 3103 & 19.3 & \\
\hline Sand+3GTX Sheets & 3 & 5 & 3816 & 23.3 & \\
\hline Sand+4GTX Sheets & 4 & 1 & 1906 & 26.8 & \multirow{3}{*}{28.6} \\
\hline Sand+4GTX Sheets & 4 & 3 & 3309 & 27.2 & \\
\hline Sand+4GTX Sheets & 4 & 5 & 4077 & 31.7 & \\
\hline
\end{tabular}

Number of Geotextile sheets per $10 \mathrm{~cm}$ of soil thickness $\left(\mathrm{N}_{10}\right)$ (column 2 of Table 2) times tensile strength of the Geotextile sheet $\left(\mathrm{T}_{0}\right)$ used in this study can be correlated linearly to the average increase in $G_{\max }$ (column 6 of Table 2) to predict the effect of geotextile spacing on shear modulus:

$$
P I G_{\max }=6.93\left(N_{10} T / T_{0}\right) \quad\left(R^{2}=0.98\right)
$$

in which $P I G_{\max }$ is percentage increase in $G_{\max }$ of parent sand, and $\mathrm{T}$ is tensile strength of the geotextile in the field.

For example, in a reinforced retaining wall project, if we decide to use high strength geotextile sheets with tensile strength 5-fold of the geotextile used in this study $\left(\mathrm{T}=5 \mathrm{~T}_{0}\right)$, and with a spacing of $25 \mathrm{~cm}$ (i.e. 2 sheets of geotextiles in 25 $\mathrm{cm})$, then $\mathrm{N}_{10}=2 \times 10 / 25=0.8$, and $P I G_{\max }=6.93\left(0.8 \times 5 T_{0} / T_{0}\right)=27.7 \%$. Similar procedure can be pursued to evaluate the scaling effect on shear modulus and damping ratio at various shear strain levels. 


\section{Conclusion}

A laboratory study was carried out to investigate the effect of geotextiles on shear modulus and damping ratio of geotextile-reinforced sands. It was shown that geotextiles enhance stiffness of the sand, and shear modulus increases with number of geotextile sheets. It was shown that a power function can successfully describe increase of maximum shear modulus with confining pressure and number of geotextile sheets. On the other hand, damping ratio increases with number of geotextile sheets, and decreases with confining pressure. Scale effect was also investigated by extrapolating the lab results to in-situ conditions. It was shown that use of geotextile-reinforced sands can lead to as high as $28 \%$ increase in maximum shear modulus.

\section{Acknowledgements}

The authors would like to thank International Institute of Earthquake Engineering and Seismology (IIEES) who provided the facilities including resonant column and hollow cylinder torsional shear devices for this research.

\section{References}

[1] S. A. Mofiz, and M. M. Rahman, "Evaluation of failure load-deformation characteristics of geo-reinforced soil using simplified approach," 11th IAEG Congress, Auckland, New Zealand, pp. 4383-4392, 2010.

[2] B. B. Broms, "Triaxial tests with fabric reinforced soil," Proc. Int. Conf. on the Use of Fabrics in Geotechnics, Ecole Nationale des Ponts et Chaussees, Laboratoire Central des Ponts et Chaussees, Paris, vol. 3, pp. 129-134, 1977.

[3] S. M. Haeri, R. Noorzad, and A. M. Oskoorouchi, "Effect of geotextile reinforcement on the mechanical behavior of sand," Geotextiles and Geomembranes, vol. 18, no. 6, pp. 385-402, 2000.

[4] N. Unnikrishnan, K. Rajagopal, and N. R. Krishnaswamy, "Behavior of reinforced clay under monotonic and cyclic loading," Geotextiles and Geomembranes, vol. 20, no. 2, pp. 117-133, 2002.

[5] R. Noorzad, and S. H. Mirmoradi, "Laboratory evaluation of the behavior of a geotextile reinforced clay," Geotextiles and Geomembranes, vol. 28, no. 4, pp. 386-392, 2010.

[6] M. Shinoda, and Y. Miyata "Damage of geogrid reinforced soil wall caused by extreme load - Japanese case histories," 11th International Conference on Geosynthetics, Seoul, Korea, 2018.

[7] R. R. Berg, B. R. Christopher, N. C. Samtani "Design of mechanically stabilized earth walls and reinforced soil slopes," Volume I, National Highway Institute Federal Highway Administration, U.S. Department of Transportation Washington, D.C., FHWA-NHI-10-024, 2009.

[8] D. G. Anderson, G .R. Martin, I. P. Lam, J. N. Wang, "Seismic analysis and design of retaining walls, slopes and embankments, and buried structures," NCHRP Report 611. National Cooperative Highway Research Program, Transportation Research Board, National Research Council, Washington, D.C., 2008.

[9] J. D. Bray, T. Travasarou, and J. Zupan, "Seismic displacement design of earth retaining structures," Proc., ASCE Earth Retention Conference 3, Bellevue, WA. American Society of Civil Engineers, Reston, VA, pp. 638-655, 2010.

[10] N. R. Krishnaswamy, and N. T. Isaac, "Liquefaction potential of reinforced sand," Geotextiles and Geomembranes, vol. 13, no. 1, pp. 23-41, 1994.

[11] R. Ziaie Moayed, M. Aliblonadi, "Effect of geotextile reinforcement on cyclic undrained behavior of sand," Soil Dynamics and Earthquake Engineering, vol. 104, pp. 395-402, 2018.

[12] S. Akbulut, and S. Pamakcu, "Evaluation of dynamic properties of geosynthetic reinforced clay Samples for Environmental Impact Practices," Environmental Earth Sciences, vol. 61, no. 7, pp. 1449-1456, 2010.

[13] M. R. Habibi, A. Shafiee, and M. K. Jafari, "Monotonic behavior of geotextile reinforced soils under discrete rotation of principal stresses," Iranian Journal of Science and Technology, vol. 38, no. C2, 2014.

[14] V. P. Drnevich, and F. E. Richart, "Dynamic prestraining of dry sands," Journal of Soil Mechanics and Foundations Divisions, Proceedings of the American Society of Civil Engineers, vol. 96, no. 2, pp. 451-469, 1940.

[15] O. H. Bobby, M. E. Kalinski, "Estimating the shear modulus of gravelly soils," Journal of Geotechnical and Geoenvironmental Engineering, vol. 131, no. 7, pp. 867-875, 2005. 
[16] J. Zhang, R. D. Andrus, C. H. Juang, "Normalized shear modulus and material damping ratio relationships," Journal of Geotechnical and Geoenvironmental Engineering, vol. 131, no. 4, pp. 453-464, 2005.

[17] M. B. Darendeli, "Development of new family of normalized modulus reduction and material damping curves," $\mathrm{Ph} . \mathrm{D}$. Dissertation, University of Texas, Austin, 2009.

[18] S. Iai, "Similitude for shaking table tests on soil-structure fluid models in $1 \mathrm{~g}$ gravitational field," Soils and Foundations, vol. 29, no. 1, pp. 105-118, 1989. 